\title{
DEBATE SOBRE LA EDUCACION SEXUAL
}

Émile Durkheim y el doctor Doléris

DURKHEIM: Creo que es inútil adelantar una discusión sobre el principio mismo de una educación sexual, pues nadie niega la necesidad de tal educación. De hecho no hay sociedad donde ella no exista; sólo que cada civilización la entiende a su manera. Igualmente, ninguna controversia puede adelantarse en lo relacionado con la higiene sexual y todas aquellas precauciones que conviene recomendar a los adultos y a los jóvenes.

Pero de la higiene el doctor Doléris pasa a la moral, y aquí tengo serias dificultades para seguirlo. Él parece admitir, en efecto, que se puede legislar sobre la moral en nombre de la higiene, pero juzga extraño la pretensión de legislar sobre la higiene en nombre de la moral. En realidad, hay allí dos funciones sociales completamente distintas que conviene estudiar por separado, salvo, si hay lugar, para tenerlas en cuenta en sus mutuas relaciones.

Desde el punto de vista moral, el verdadero problema que surge es el de saber por qué la continencia es un deber y cómo se pueden explicar las razones de este deber a los jóvenes. En toda la exposición del Dr. Doléris no encuentro más que tina sola mención a este asunto; y además no está tratado en sí mismo. Doléris se limita a mostrar que contrayendo uniones libres, nos exponemos a correr riesgos físicos y molestias morales (nacimiento de hijos naturales, perturbaciones domésticas, consecuencias de estas perturbaciones). Es evidente que dado que en la sociedad actual hay un matrimonio organizado, toda unión sexual fuera del matrimonio necesariamente engendra problemas sociales de diversa índole, y además puede poner en peligro la salud. Pero este no es el problema. Se trata de saber si, y cómo, podemos hacer comprender a los jóvenes que el estado del matrimonio se justifica, y que el comercio sexual fuera de él es inmoral. Este asunto requiere más atención que la solución que ha sido dada en relación con la enseñanza de la higiene sexual que tanto preocupa al Dr. Doléris. Pues para poder hacer sentir a los jóvenes el aspecto moral del comercio sexual, es tal vez necesario no hacer uso de conocimientos científicos sino con una discreción y una reserva que el médico abandonado a sí mismo no percibe con la claridad necesaria.

El Dr. Doléris, en efecto, parte del axioma de que el carácter misterioso atribuido por la opinión pública y por las creencias religiosas al acto sexual, no es más que un simple prejuicio que no corresponde a la realidad. Si es por lo tanto una supervivencia, es una supervivencia de un pasado lejano y de costumbres singularmente tenaces. Sin duda, en cada época, la manera de considerar el acto sexual parece solidario de todo un conjunto de creencias confesionales y, por ejemplo, de dogmas cristianos. Por consiguiente, el abandono de estas creencias, de estos dogmas, parece entrañar necesariamente el abandono de la concepción en apariencia mística del acto sexual. Pero cuando un sentimiento colectivo se ha afirmado con persistencia a lo largo de toda la historia, podemos estar seguros de que está fundado en los hechos, de la misma manera que no serían razonablemente defendibles las fórmulas confesionales por las cuales se los ha

\footnotetext{
* Intervención de Durkheim en una discusión en la Societé de Philosphie sobre "La educación sexual'. Publicado orginalmente en el Bulletin de La Societé française de philosophie, No. 11, Paris, 1911, pp. 33-34.
} 
justificado durante el pasado. Ahora bien, las religiones más recientes y más refinadas no son las únicas que han atribuido al acto sexual este carácter singular; las más primitivas y las más burdas son igualmente unánimes en ver aquí un acto trascendental, solemne, religioso.

Ideas tan generalizadas como estas, no se deben a una simple aberración o a un engaño del cual los hombres han sido objeto durante siglos. El símbolo confesional puede traducir imperfectamente la realidad moral a la cual corresponde, pero ello no quiere decir que esté vacío de toda realidad. Por el contrario, podemos considerar como cierto que corresponde a algún elemento de lo real, es decir, a algún sentimiento efectivamente sufrido por los hombres de todos los tiempos. El problema que surge entonces, consiste en buscar cuál es ese sentimiento, de qué está hecho, cuáles son sus orígenes, esto es, cuál es el aspecto de la vida humana que el expresa.

No puedo, lógicamente, emprender el análisis de un sentimiento tan complejo; debo limitarme aquí sólo a hacer algunas indicaciones. Cuando decimos que el acto sexual tiene algo misterioso, entendemos que no debe ser asimilado a los actos de la vida corriente, que es excepcional, que por ciertos aspectos es problemático y desconcertante, que despierta en nosotros sentimientos contradictorios. Al mismo tiempo que nos atrae, se expresa aquello que nos choca, nos ofende, nos repugna. Ahora bien, parece que este sentimiento sea el resultado de una pura ilusión. Si existe el pudor, el acto sexual es el acto impúdico por excelencia; viola el pudor, es su negación, y puesto que el pudor es una virtud, hay en él un carácter inmoral. Pero por otro lado, no hay ningún acto que ligue con más fuerza a los seres humanos; tiene un poder asociativo, y por consiguiente, de valor moral incomparable. ¿Es extraño que frente a una relación tan compleja, tan ambigua, la conciencia moral quede vacilante, confundida, perpleja, dividida dentro de ella misma? No puede pregonarlo, condenarlo, alabarlo, reprobarlo y sobre todo serle indiferente, y si lo arroja en sentido contrario, el sexo no tiene cara por donde la deje insensible. Es por esto que la conciencia moral lo acepta, pero teniendo en cuenta que está rodeado de sombra y misterio.

Por somero que sea este análisis, es suficiente para hacer sentir que el acto sexual no es un acto cualquiera, que por el contrarío, no se parece a ningún otro y por su extrañeza tiene un lugar aparte en la vida moral. Si esto es así, la educación sexual carecería evidentemente de objetivo si no fuera entendida de manera que haga sentir a los jóvenes el carácter original, sui generis de este acto singular; pues lo que importa ante todo es que dé una idea adecuada de él; que lo haga comprender tal como es. Ahora bien, temo que la enseñanza sexual en la forma como el médico nos ha llevado a concebirla, no tiene en cuenta esta necesidad primordial de reserva, de discreción que ella implica. Si, como parece expresarlo el Dr. Doléris, hablamos del acto sexual como un acto ordinario de la vida física, en realidad lo estamos desnaturalizando, le estamos quitando aquello que para los hombres es el elemento esencial; pues para ellos está lejos de reducirse a los meros movimientos materiales implicados en este acto. El carácter contradictorio, misterioso, excepcional que le reconoce la conciencia pública, hace parte de su naturaleza. ¿Cómo conservarla si nos referimos a el sin velos, sin ninguna clase de precauciones? ¿Y qué resultados morales obtendríamos si lleváramos a la juventud a no ver en el comercio sexual sino la manifestación de una función biológica, comparable a la digestión y a la circulación?

Lejos estoy de negar la utilidad de una enseñanza científica que le aclare a los dos sexos la naturaleza física de este acto. Pero cuando escucho al Dr. Doléris tratar como supersticiones a las concepciones que hacen del acto sexual un acto aislado, oscuro, 
confuso y, en cierto sentido, misterioso, me pregunto si no pierde de vista toda una dimensión del problema, y si a pesar de todo percibe cuán delicado y difícil es impartir esta enseñanza. Temo, en una palabra, que simplifique un poco el asunto. No se trata de que nos sacrifiquemos a una pudibundez burguesa, pero sí de inculcar a nuestros niños un sentimiento sin el cual la educación sexual pecaría por la base. Este sentimiento las religiones lo han inculcado por los procedimientos que conocemos. Se debe emplear otro, pero no estamos en lo cierto cuando creemos que las religiones se han equivocado totalmente sobre la naturaleza del objetivo a seguir.

Dr. DOLÉRIS: No tengo nada que responder a lo dicho por Durkheim; no poseo la competencia si tuviera que tratar los problemas que él ha expuesto y admito que yo me coloqué y esperaba conducirlos a ustedes a un punto de vista totalmente diferente.

Permaneciendo, como yo puedo hacerlo, en el terreno de la ciencia, y en particular en el de la ciencia biológica, pues es de ella de la que se trata, me limito a hacer notar que a pesar de todo, que a pesar de las opiniones y de los esfuerzos de los hombres por ocultarse el verdadero sentido y la importancia fundamental, el acto sexual permanece fundamentalmente como acto biológico; aquel sin el cual ninguna vida material es posible, alrededor del cual por consecuencia se mueve forzosamente toda vida humana. Parece entonces que lo contrario ha debido producirse y que este acto esencial, primordial, no debería ser relegado a una penumbra misteriosa, verse opuesto sin cesar a los sentimientos de vergüenza y de pudor, conminado a encontrarse aparte y como al margen de todas las acciones humanas, normales y respetadas. Deberá entonces, y este es el oficio del sociólogo, investigarse las causas reales que han llevado a considerar este acto como un acto misterioso y temible, que ha habituado a los hombres a disimular de tan diversas maneras una realidad tan clara y simple. Ahora bien, yo creo sin duda que podemos encontrar en estos prejuicios principalmente razones utilitarias. En Turquía por ejemplo, la poligamia es permitida en la medida en que los hombres puedan sostener a sus numerosas mujeres; la monogamia no es más que la situación del hombre pobre incapaz de satisfacer el mantenimiento de varias mujeres; y queda, por supuesto, una cantidad de hombres fuera de la posibilidad de proveerse de mujeres, permaneciendo reducidos a vivir entre ellos en una especie de promiscuidad.

Sucede lo mismo con la mayor parte de los antiguos prejuicios en materia sexual y matrimonial; los motivos podrían ser encontrados en las condiciones del orden social o económico.

Yo creo entonces que Durkheim, cuando los acoge tan fácilmente, sufre todavía la influencia de una educación, de un medio particular, y que esta influencia le impide considerar irremediablemente el acto sexual tal como es: simple y fundamental. Es esto lo que yo traté de hacer: quise poner al niño en presencia del hecho sexual con la ayuda de una educación apropiada que no tienda a disfrazar por algún tiempo la realidad. Es haciéndolo, por el contrario, percibir poco a poco, sin rodeos y sin afectaciones, que se llegará sin duda a mejorar, desde el punto de vista de las relaciones sexuales, el estado actual. No deseaba partir de prejuicios reinantes, pero sí del estado actual de cosas que estos prejuicios no hacen más que enmascarar, a fin de buscar los medios, no para interpretar o respetar aquellos prejuicios, sino para modificar en cuanto sea posible este estado de cosas a través de la educación.

En cuanto a la enseñanza, estoy de acuerdo con Durkheim que se debe ser muy prudente, que la más perfecta decencia y simplicidad se imponen en tal materia y que el maestro debe siempre guardar la reserva que conviene. Sobre todo si se trata de las 
jóvenes. Yo he insistido sobre este punto en la ponencia que ustedes conocen. Creo que a las jóvenes -y por haberlo experimentado yo mismo - puede dárseles una educación sexual muy completa, diciéndoles solamente lo más simple y lo más científico. Podemos hacerles conocer poco a poco las cosas de la reproducción evitando todo cuadro vulgar y respetando las susceptibilidades.

Para convencerse de que un conocimiento claro y preciso de estas cosas no lleva a la inmoralidad, es suficiente pensar en las jóvenes que trabajan en nuestras facultades de medicina, que disecan sin cesar los cuerpos humanos, que conocen todos los mecanismos de la reproducción, y que sin embargo, guardan una actitud, una conducta y una mentalidad absolutamente decentes y totalmente irreprochables. Es porque diariamente tengo bajo mis ojos tal espectáculo que me atrevo a afirmar la eficacia y la necesidad de una enseñanza sexual sin tapujos y sin reticencias de ninguna clase.

DURKHEIM: Me limitaré a precisar mi pensamiento sobre dos puntos, sin regresar al fondo mismo del debate.

No es de ninguna manera como hombre que yo he hablado del carácter misterioso del acto sexual; por el contrario, sólo y exclusivamente como sociólogo. Soy consciente de que no le confiero a la educación el sentimiento que someramente he tratado de analizar. Este carácter oscuro, misterioso, temible del acto sexual, me ha sido revelado por las investigaciones históricas y etnográficas y recuerdo el momento mismo en el cual he sido sacudido por la extrema generalidad del hecho y de su notable alcance.

Por otro lado, cuando hablo de misterio y de oscuridad, no busco con esto inspirarle al niño una impresión de miedo y de respeto supersticioso e irracional; estoy lejos de querer excluir la razón del dominio de las relaciones sexuales. Creo, por el contrario, que ella debe aplicarse allí sin cesar. Sólo que no debe ser aplicada únicamente a los gestos exteriores que los manifiestan y que estudia el fisiólogo, sino también a los sentimientos, las ideas, las instituciones que dan a estas relaciones su forma específicamente humana. Es por esto que se puede y se debe mostrar al niño cómo este doble aspecto del acto sexual que señalé hace un momento, se encuentra estrechamente ligado a las ideas sociales y morales de hoy en día; y que las necesidades de esta enseñanza moral son las que obligan, creo, a una gran discreción en la enseñanza de la higiene sexual.

PAUL BUREAU: Pensé que Durkheim iba a responder la pregunta, que es, como él mismo nos lo ha dicho al comienzo de sus observaciones, la sola, la única pregunta que lleva a esta discusión: ¿por qué existe una moral sexual y qué razones válidas, ubicadas en la conciencia, se pueden dar a quienes se les pide que la observen? ¿cuál es, en otros términos, la razón de la continencia? (...)

En lo que concierne a la educación de la voluntad que tanto preconiza Dominique Parodi, soy el primero en afirmar su importancia y lo he indicado muy explícitamente en mi intervención. Pero también creo en la necesidad de hacer intervenir las consideraciones utilitarias, que pueden actuar como un freno muy eficaz; si nos limitamos a las máximas teóricas, no podremos salir de la abstracción y alcanzar verdaderamente el espíritu del adolescente. En el fondo además, como lo indicaba hace un momento, estas son consideraciones utilitarias que están en el fundamento de las ideas religiosas o filosóficas en materia sexual, pero permanecen siempre confusas, encubiertas, en lugar de manifestarse claramente a la luz del día. La razón del carácter misterioso del acto sexual, no debe ser buscado fuera de esto. Contra el abuso que en la mayoría de los pueblos de 
la antigüedad venían entrabando las relaciones sexuales, las sociedades reaccionaron; de allí provienen, sin duda, las reglas exageradas y torpes contrarias a la abstención proclamadas por las religiones y las filosofías en todos los tiempos con un fin de defensa social.

DURKHEIM: Responderé simultáneamente a las preguntas planteadas por Bureau y Parodi.

Boureau se ubica abiertamente en el punto de vista confesional; nos ha indicado cómo pretende justificar la continencia a los ojos del joven. Ahora bien, me siento sacudido por la prodigiosa distancia que tal justificación deja entre los principios sobre los cuales se funda y el hecho particular, el precepto determinado del cual pretende dar cuenta. Estos principios, son por ejemplo, afirmaciones de este género: tenemos destinos maravillosos que se abren delante de nosotros; la vida humana, en cada uno de sus momentos, tiene un valor incomparable, etc. Sobre tales principios todo se podría entender sin grandes dificultades. Es cierto que el hombre es algo completamente aparte en el mundo, que le atribuimos un valor incomparable en relación con los demás seres. Lo que resulta de esta idea general, es que todos los actos consumados por el hombre tienen, por esta razón, una significación particular que no suelen ser los mismos actos considerados en el animal. La manera como Bureau nos presenta el acto sexual no posee pues ningún tratamiento particular de este acto: en lugar de considerarlo en sí mismo y de explicar su especificidad, se limita a clasificarlo entre los actos humanos. ¿Pero qué es lo que entre estos actos singulariza al acto sexual? Bureau no lo dice. Que este acto presenta características que le son propias, Bureau lo reconoce, puesto que lo separa de los actos corrientes como comer y beber, y porque encuentra en el también algo particularmente problemático. Si este carácter problemático, misterioso, le viene, como lo he indicado, de un lado como algo necesariamente inmoral, y de otro como francamente moralizador, será necesario para resolverlo, o al menos, para abordar el problema de la moral sexual, explicar sus dos aspectos contradictorios, dar cuenta de su oposición y de su correlación; pero no podremos contentarnos con la explicación confesional de Bureau, que a causa de su extrema generalidad deja escapar todo aquello que ha caracterizado el hecho en cuestión. Regreso ahora a este asunto.

Primero que todo, haré notar que no es un problema que pueda ser resuelto a lo largo de una rápida discusión y con la ayuda de algunas fórmulas. Se deberá estudiar el acto sexual en todos sus concomitantes sociales, sus repercusiones domésticas, etc. Cuando nos damos cuenta de la complejidad de los hechos sociales, se comprende que el problema supone un conjunto de investigaciones. $Y$ para no ubicarme en una actitud meramente negativa, trataré de indicar cómo es posible servirse de ellas para justificar esta regla de nuestra moral actual, sin recurrir a ningún postulado confesional.

En primer lugar, habrá necesidad de explicar las razones de ser del matrimonio, de mostrar cómo está ligado a toda nuestra moral doméstica, y a continuación, cómo el comercio sexual, fuera del matrimonio, perturba nuestra organización familiar: lo cual es una primera razón para establecer la inmoralidad. Pero ella no aparece sino de una manera indirecta y mediata. También creo que la mejor forma de impresionar el espíritu de un joven, es hacerle comprender las razones de este carácter singular, inquietante del acto sexual, del cual he hablado hace un momento; pues es de esta característica que el joven no se librará tan pronto.

Kant tenía ya el sentimiento de que en el comercio sexual hay algo que ofende al sentimiento moral: consiste, dice él, en que un individuo sirva de instrumento de placer 
para otro, lo que es contrario a la dignidad de la persona humana. Pero la razón, creo, de la inquietud moral que nos causa este acto es más general y profundo. El sentimiento que está en la base de nuestra moral es el respeto que el hombre inspira al hombre. A causa de este respeto, nosotros nos mantenemos a distancia de nuestros semejantes, y ellos nos tienen a distancia; huimos de los contactos íntimos, no los permitimos, esquivamos nuestro cuerpo lo mismo que nuestra vida interior a las miradas indiscretas; nos cubrimos ante los otros, nos aislamos, y este aislamiento es a la vez el signo y la consecuencia del carácter sagrado del cual lo hemos investido. Tocar algo santo sin emplear las precauciones respetuosas que prescribe el rito, es profanar, cometer un sacrilegio. Al mismo tiempo, hay una especie de profanación al no respetar las fronteras que separan a los hombres, a violar los límites, a penetrar indebidamente en otro. Esto es lo que da lugar al sentimiento y al deber del pudor, sea físico o moral. Por lo tanto, no hay necesidad de mostrar que en el acto sexual esta profanación tiene una excepcional intensidad, puesto que las dos personalidades en contacto se pierden la una en la otra. Jamás el abandono de esta reserva que no es sino otro aspecto de nuestra dignidad es tan completa. He aquí en lo que consiste el germen de inmoralidad fundamental que contiene en sí este acto tan curiosamente complejo.

Pero, al mismo tiempo, contiene en sí mismo también la forma de borrar y rescatar esta inmoralidad constitucional. Esta profanación, en efecto, produce, por otra parte, la comunión más íntima que puede existir entre dos seres Conscientes. Por efecto de esta comunión, las dos personas que se unen no son sino una en el fondo; los límites que primitivamente la circunscribían, son desplazados y llevadas más lejos; una personalidad nueva que envuelve y comprende las otras dos ha nacido. Cuando esta fusión es crónica o cuando la nueva unidad que así se ha formado se hace estable, desde entonces la profanación desaparece, puesto que no hay presencia de dos personas distintas y separadas sino de una sola. Este resultado no llega más que a esta condición. Al contrario, cuando los dos individuos después de estar unidos se separan de nuevo, cuando cada uno de ellos, después de darse al otro, retoma su independencia, la profanación queda integral y sin compensación. He aquí por qué la moral protesta contra la unión libre, abstracción hecha de las consecuencias que pueda tener sobre el orden doméstico. La conciencia pública siente que el acto sexual, por sí mismo, une; que esta fuerza unificadora le es inherente, y que al cortar estos lazos naturales, al no respetarlos, agravamos aún más lo que este acto tiene ya por sí mismo de moralmente chocante. De aquí viene la molestia moral que sentimos cuando dos esposos divorciados se encuentran uno frente al otro; nos damos cuenta de lo que hay de anormal en la situación de dos individuos que se tratan mutuamente como extraños, cuando en realidad ellos no son misterio el uno para el otro. Esto no quiere decir, sin duda, que el divorcio no sea una necesidad que se imponga. Pero no deja de tener, en algunos de sus efectos, algo desconcertante que hay que saber reconocer.

Estas indicaciones son tal vez suficientes para entrever cómo podemos explicar racionalmente que el acto sexual es un acto profundo y solemne, que liga los sujetos que pone en relación, aún cuando no haya sido contraído siguiendo las procedimientos necesarios para que estas obligaciones sean jurídicamente sancionadas (...) 